\title{
Skin testing for hypersensitivity and cross-reactivity between proton pump inhibitors
}

\author{
Philip $\mathrm{H} \mathrm{Li}{ }^{*}$
}

Hong Kong Med J 2020;26:450.e1-2

https://doi.org/10.12809/hkmj198267

A 44-year-old woman presented to our anaphylaxis clinic with first episode of anaphylaxis. She had no known prior food or drug allergies. She was previously prescribed esomeprazole $20 \mathrm{mg}$ daily as required for dyspepsia by her private physician, but took it only very occasionally. Two months previously she took one tablet of esomeprazole $(20 \mathrm{mg})$ and one of paracetamol $(500 \mathrm{mg})$ together with a slice of plain bread for abdominal discomfort and influenza-like symptoms. Within 10 minutes, she experienced generalised pruritus and collapsed at home. She awoke after hitting the floor and telephoned for an ambulance. She was treated with intramuscular adrenaline in the ambulance because systolic blood pressure had fallen to $<80 \mathrm{~mm} \mathrm{Hg}$. Initial investigations revealed a significant rise in acute tryptase $(12.3 \mathrm{ng} / \mathrm{mL})$ with a normal baseline level $(2.1 \mathrm{ng} / \mathrm{mL})$. Initially wheat or wheat-dependent cofactor augmented anaphylaxis was suspected. She was advised to avoid wheat, cyclooxygenase inhibitors, and proton pump inhibitors (PPI) until review.

Results for specific immunoglobulin E to wheat and omega-5-gliadin were negative. Skin prick test (SPT) to wheat solution (Inmunotek, Madrid, Spain) and prick-to-prick with the index bread slice was also negative. Skin prick test and intradermal tests (IDT) to paracetamol (both $100 \mathrm{mg} / \mathrm{mL}$, GlaxoSmithKline, London, United Kingdom) were also negative. The patient tolerated an oral challenge with $500 \mathrm{mg}$ of paracetamol together with a slice of the same index bread with no adverse reaction.

The SPT $(8 \mathrm{mg} / \mathrm{mL})$ and IDT $(8 \mathrm{mg} / \mathrm{mL}$, $0.8 \mathrm{mg} / \mathrm{mL}$ and $0.08 \mathrm{mg} / \mathrm{mL}$; AstraZeneca, Bedfordshire, United Kingdom) were performed and are shown in the Figure. Skin prick test to histamine (positive control) and normal saline (negative control) was positive at $5 \mathrm{~mm}$ and negative at $0 \mathrm{~mm}$, respectively. Skin prick test to esomeprazole was borderline positive with a $3-\mathrm{mm}$ wheal and flare. Intradermal test to esomeprazole was positive at concentrations of $8 \mathrm{mg} / \mathrm{mL}, 0.8 \mathrm{mg} / \mathrm{mL}$ and $0.08 \mathrm{mg} / \mathrm{mL}$; with $18-\mathrm{mm}, 8-\mathrm{mm}$ and $3-\mathrm{mm}$ wheal expansion, respectively. The SPT and IDT with $8 \mathrm{mg} / \mathrm{mL}$ and $0.8 \mathrm{mg} / \mathrm{mL}$ were negative in a healthy control (the author) as shown in the Figure. To assess for potential cross-reactivity, SPT $(4 \mathrm{mg} / \mathrm{mL})$ and IDT $(4 \mathrm{mg} / \mathrm{mL}$ and $0.4 \mathrm{mg} / \mathrm{mL}$ ) to pantoprazole were also performed and are also shown in the Figure. The SPT was negative, but IDT was positive with $4 \mathrm{mg} / \mathrm{mL}$

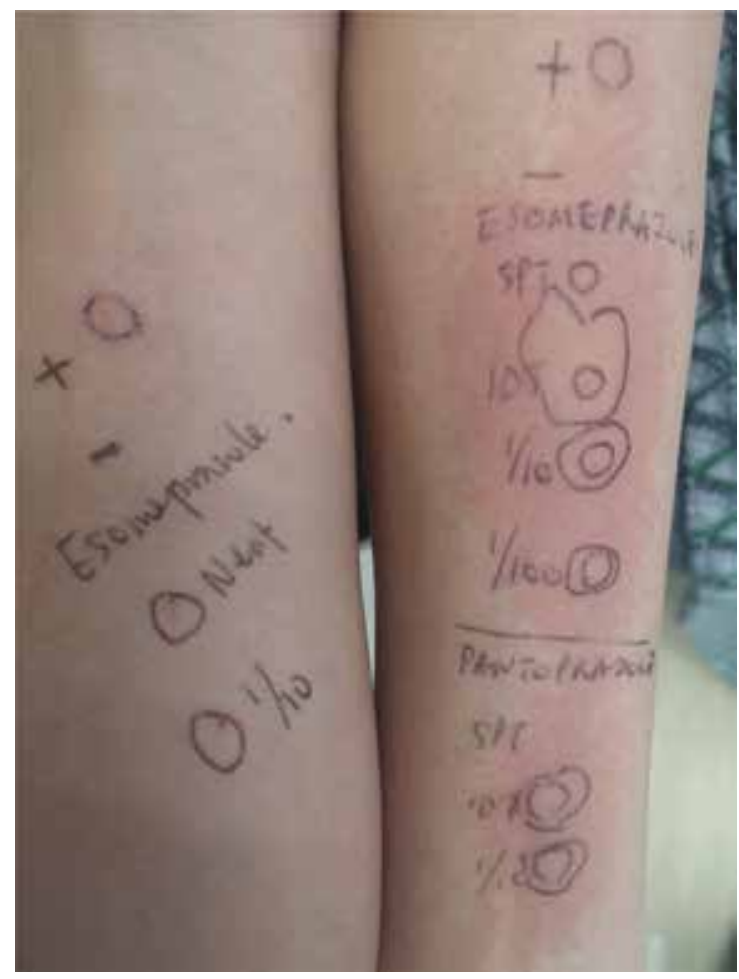

FIG. Left: Intradermal tests to esomeprazole in healthy control (neat, I: I0 dilution). Right: Skin prick and intradermal tests to esomeprazole (neat, I:I0 and I:I00 dilutions) and pantoprazole (neat and $\mathrm{I}: 10$ dilution)

and $0.4 \mathrm{mg} / \mathrm{mL}$ dilutions with $7-\mathrm{mm}$ and $4-\mathrm{mm}$ wheal expansion, respectively.

She was diagnosed with severe type I hypersensitivity to esomeprazole with crosssensitisation to pantoprazole. Drug provocoation testing was not indicated in view of the compatible clinical history, strongly positive skin tests, and high risk of anaphylaxis. The patient declined testing with other PPI and was advised to avoid the entire class until further workup. She was prescribed famotidine $20 \mathrm{mg}$ twice a day for her dyspepsia with no adverse effects.

This is the first reported case in Hong Kong of PPI anaphylaxis and demonstrates the utility of skin testing to assess potential cross-reactivity. Although relatively uncommon, reports of hypersensitivity to PPI are increasing, in parallel with their increasing use worldwide. The majority of hypersensitivity 
reactions appear to be of the immediate type. ${ }^{1}$ Previous exposure to esomeprazole may have been initial sensitising events. Despite common misconception, clinicians should bear in mind that prior tolerance of a certain drug does not preclude it as a future cause of drug allergy. Although patterns of cross-reactivity among various PPIs have been reported, these remain controversial and a thorough allergological workup should be performed for every patient. ${ }^{2}$ Clinicians are reminded to be vigilant of this uncommon cause of anaphylaxis and beware of potential cross-reactivity. The S PT a nd I DT have high specificity, b ut $\mathrm{p}$ atients $\mathrm{w}$ ith $\mathrm{s}$ uspected PPI hypersensitivity and negative skin tests should undergo drug provocation tests to confidently exclude this important diagnosis. ${ }^{3}$

\section{Author contributions}

The author contributed to the concept or design, acquisition of data, analysis or interpretation of data, drafting of the manuscript, and critical revision for important intellectual content. the The author had full access to the data, contributed to the study, approved the final version for publication, and takes responsibility for its accuracy and integrity.

\section{Conflicts of interest}

The author has disclosed no conflicts of interest.

\section{Funding/support}

This pictorial medicine paper received no specific grant from any funding agency in the public, commercial, or not-forprofit sectors.

\section{Ethics approval}

The patient consented to this publication.

PH Li *, MRCP, FHKCP

Division of Rheumatology and Clinical Immunology, Department of Medicine, The University of Hong Kong, Queen Mary Hospital, Pokfulam, Hong Kong

* Corresponding author: liphilip@hku.hk

\section{References}

1. Otani IM, Banerji A. Immediate and delayed hypersensitivity reactions to proton pump inhibitors: evaluation and management. Curr Allergy Asthma Rep 2016;16:17.

2. Tourillon C, Mahe J, Baron A, et al. Immediate-type hypersensitivity cross-reactions to proton pump inhibitors: a descriptive study of data from the French National Pharmacovigilance Database. Int Arch Allergy Immunol 2019;178:159-66.

3. Kepil Özdemir S, Yilmaz I, Aydin Ö, et al. Immediatetype hypersensitivity reactions to proton pump inhibitors: usefulness of skin tests in the diagnosis and assessment of cross-reactivity. Allergy 2013;68:1008-14. 